\title{
Evaluación de factores de virulencia en cepas de Salmonella Typhimurium aisladas de cuyes (Cavia porcellus) enfermos y sanos
}

\author{
Evaluation of virulence factors of strains of Salmonella Typhimurium isolated \\ from diseased and healthy guinea pigs (Cavia porcellus)
Carla Duran Gonzalez', Luis Luna Espinoza', Dennis Carhuaricra Huamán', Guillermo Salvatierra Rodríguez ${ }^{2}$, Raúl Rosadio Alcántara ${ }^{1}$, \\ Lenin Maturrano Hernández ${ }^{1,3}$
}

\section{Resumen}

El presente estudio evaluó la presencia de 10 genes codificantes de diversos factores de virulencia de importancia biológica en un total de 100 aislados de Salmonella Typhimurium, donde 90 aislados procedían de cuyes enfermos y 10 de cuyes aparentemente sanos. El ADN fue extraído de todos los aislados y se analizaron mediante la técnica de PCR múltiple para evaluar la presencia de los genes $\operatorname{spv} B, \operatorname{spi} A, \operatorname{cdt} B, \operatorname{sip} B$, tolC, sitC, lpfC, sifA, sop $B$ y pefA. Se obtuvo un patrón genético similar, con frecuencias

\footnotetext{
${ }^{1}$ Unidad de Biología y Genética Molecular, Facultad de Medicina Veterinaria, Universidad Nacional Mayor de San Marcos, Lima, Perú

${ }^{2}$ Laboratorio de Genómica Microbiana, Universidad Peruana Cayetano Heredia, Lima, Perú

${ }^{3}$ E-mail: amaturranoh@unmsm.edu.pe
}

Artículo derivado del trabajo de tesis para optar el título profesional de Médico Veterinario de la Bach. Carla Gabriela Duran Gonzales, titulado "Evaluación de factores de virulencia de cepas de Salmonella spp aisladas de cuyes (Cavia porcellus) enfermos y sanos» en la Universidad Nacional Mayor de San Marcos

Recibido: 27 de octubre de 2019

Aceptado para publicación: 19 de septiembre de 2021

Publicado: 27 de octubre de 2021

CLos autores. Este artículo es publicado por la Rev Inv Vet Perú de la Facultad de Medicina Veterinaria, Universidad Nacional Mayor de San Marcos. Este es un artículo de acceso abierto, distribuido bajo los términos de la licencia Creative Commons Atribución 4.0 Internacional (CC BY 4.0) [https:// creativecommons.org/licenses/by/4.0/deed.es] que permite el uso, distribución y reproducción en cualquier medio, siempre que la obra original sea debidamente citada de su fuente original 
de detección variables mayores al $60 \%$, tanto en aislados de cuyes sanos como enfermos, excepto el gen $c d t B$, el cual no fue detectado. No hubo diferencias significativas entre la presencia de factores de virulencia de Salmonella Typhimurium aisladas de cuyes enfermos y de cuyes aparentemente sanos.

Palabras clave: cuy, Salmonella Typhimurium, factores de virulencia, PCR Múltiple

\section{AbSTRACT}

The present study evaluated the presence of 10 genes encoding various virulence factors of biological importance in 100 Salmonella Typhimurium isolates, where 90 isolates came from sick guinea pigs and 10 from apparently healthy ones. DNA was extracted from all isolates and analyzed using the Multiple PCR technique to assess the presence of the spvB, spiA, $c d t B, \operatorname{sip} B, t o l C, \operatorname{sit} C, \operatorname{lpf} C, \operatorname{sif} A, \operatorname{sop} B$ and pefA genes. A similar genetic pattern was obtained, with variable detection frequencies greater than $60 \%$, both in healthy and sick guinea pigs, except for the $c d t B$ gene, which was not detected. There were no significant differences between the presence of Salmonella Typhimurium virulence factors isolated from sick guinea pigs and apparently healthy guinea pigs.

Key words: guinea pig, Salmonella Typhimurium, virulence factors, PCR Multiplex

\section{INTRODUCCIÓN}

El cuy (Cavia porcellus), como cualquier especie productiva, es susceptible a sufrir enfermedades que traen consigo pérdidas económicas, influenciadas directamente por las deficientes condiciones de crianza y alimentación y niveles de bioseguridad en los lugares de crianza (Matsuura et al., 2010; Morales S, 2012). Dentro de las enfermedades, una de las más graves es la salmonelosis, causada en el $95 \%$ de casos por el serotipo Typhimurium (Chauca, 1997). Esta origina morbilidad entre 0.87 y $52.7 \%$ y mortalidad hasta del 95\%, con manifestaciones clínicas variadas (Morales et al., 2007).

Se ha demostrado la existencia de $S$. Typhimurium en aislados de cuyes en aparente buen estado de salud utilizados como reproductores (Chero et al., 2017), lo que indicaría que estos animales actuarían como portadores y diseminadores de la enfermedad. Con respecto al proceso patogénico en la salmonelosis, existe un grupo de genes que actúan de manera coordinada, codificando factores solubles que modifican la fisiología celular del hospedero o protegen a la bacteria de la acción antimicrobiana para asistir al patógeno a expresar su virulencia en la célula hospedero y finalmente manifestar la signología (Murugkar et al., 2003; van Asten y Van Dijk, 2005; Martínez, 2007).

Estos factores de virulencia, evaluados previamente en el modelo murino, se encuentran en diversos serovares de Salmonella, incluido Salmonella Typhimurium, los cuales son codificados por genes como $s p v B$, inv $A$, tolC, $\operatorname{sop} B$, spiA, entre otros; que cumplen funciones biológicas asociadas al reconocimiento del hospedero, adhesión e invasión, supervivencia y muerte de macrófagos, etc., con las que se posibilita el desarrollo y mantenimiento de la enfermedad (Skyberg et al., 2006). Por ello, es importante conocer los factores de virulencia que existen en $S$. Typhimurium aislados de cuyes con salmonelosis y de cuyes aparentemente sa- 
nos. Así, el presente estudio tuvo como objetivo evaluar los de genes de virulencia $s p v B$, spi $A, c d t B, \operatorname{sip} B$, tolC, sitC, lpfC, sif $A, \operatorname{sop} B$ y pef $A$ presentes en $S$. Typhimurium de cuyes enfermos y cuyes aparentemente sanos.

\section{Materiales y Métodos}

\section{Material Experimental}

Se analizaron 100 aislados de Salmonella Typhimurium de cuyes, conformados por 10 aislados de hisopados vaginales/rectales de cuyes hembra aparentemente sanas y 90 aislados recuperados de muestras de órganos de cuyes diagnosticados con salmonelosis, provenientes de granjas de producción de Huaral, Manchay y Huancayo (Perú). Dicho material fue colectado en estudios previos, enmarcados en el proyecto «Desarrollo de una vacuna para el control y prevención de la salmonelosis en la producción de cuyes» Contrato N. ${ }^{\circ}$ 362- PNICP-PIAP-2014 (Innóvate Perú), e identificados a través de PCR convencional, detectando la presencia de los genes invA (presente en S. enterica subsp enterica) y flic $C$ (presente en el serovar Typhimurium)..

El procesamiento de las muestras se realizó en la Unidad de Biología y Genética Molecular de la Facultad de Medicina Veterinaria de la Universidad Nacional Mayor de San Marcos, Lima, Perú.

\section{Reactivación de Aislados}

Los 100 aislados de $S$. Typhimurium fueron reactivados siguiendo el protocolo establecido por Sánchez y Corrales (2005): Cada aislado fue sembrado por agotamiento en una placa de agar Xilosa Lisina Desoxicolato (XLD, Britania) e incubados a $42{ }^{\circ} \mathrm{C}$ por 24 $\mathrm{h}$ en condiciones aeróbicas. Luego se verificó el crecimiento de colonias características color rojo, lactosa negativas, diámetro de 1.5 $\mathrm{mm}$ y ligeramente convexas, las cuales pueden presentar un precipitado color negro al centro debido a la producción de sulfuro de hidrógeno (Flores, 2003). Una vez confirmado el crecimiento de salmonellas puras en placa, se tomó una colonia por cada aislado y se inoculó en $2 \mathrm{ml}$ de caldo Luria Bertani (LB, Merck), manteniendo en incubación con agitación a $37^{\circ} \mathrm{C}$ por $3 \mathrm{~h}$.

\section{Extracción de ADN}

Luego del proceso de incubación y verificando la turbidez de la solución debido al crecimiento bacteriano, se extrajo el ADN de cada muestra mediante el método de ebullición, de acuerdo con el protocolo de Karimnasab et al. (2013). Brevemente, los cultivos fueron centrifugados a $15000 \mathrm{~g}$ por 5 min, se descartó el sobrenadante y se homogenizó con $50 \mu 1$ de agua ultrapura estéril libre de DNasas y RNasas (Invitrogen) a fin de resuspender el pellet formado. Posteriormente, las muestras se sometieron a ebullición $\left(100^{\circ} \mathrm{C}\right)$ por $5 \mathrm{~min}$, seguidos de una centrifugación a $15000 \mathrm{~g}$ durante $5 \mathrm{~min}$. Finalmente, se recuperaron los sobrenadantes y se colocaron en viales de $600 \mu 1$. Finalmente se cuantificaron las concentraciones de ADN obtenidas con el espectrofotómetro (260 $\mathrm{nm})$, obteniéndose valores de concentración entre 35-75 ng/ $\mu 1$ de ADN.

\section{PCR Múltiple}

Para evaluar los 10 genes de virulencia de $S$. Typhimurium presentes en los aislados se utilizó la técnica de PCR Múltiple, haciendo uso de los cebadores descritos por Skyberg et al. (2006) (Cuadro 1). Se realizaron dos PCR múltiples, la primera reacción para amplificar los genes $s p v B, \operatorname{spi} A, \operatorname{sip} B$, tolC y $c d t B$, y la segunda, para amplificar los genes sitC, lpfC, sifA, $\operatorname{sop} B$ y pefA. La mezcla para las PCR Múltiples consistió en ambos casos de Buffer 10X PCR (100 mM KCl, $100 \mathrm{mM}$ Tris- $\mathrm{HCl}, 20 \mathrm{mM}$ de $\mathrm{MgCl}_{2}$ ), $0.25 \mathrm{mM}$ de desoxinucleótido trifosfato, mix de cebadores (cada cebador a $0.5 \mathrm{mM}$ ), $25 \mathrm{mM}$ de $\mathrm{MgCl}_{2}$, $1 \mathrm{U}$ de Taq Polimerasa; y $2.5 \mu 1$ de ADN, en un volumen total de $20 \mu \mathrm{l}$ para cada muestra. 
Cuadro 1. Secuencia y tamaño (pb) de los cebadores utilizados en la PCR Múltiple

\begin{tabular}{|c|c|c|}
\hline Gen & Secuencia $5^{\prime}-3^{\prime}$ & $\begin{array}{c}\text { Tamaño } \\
(\mathrm{pb})\end{array}$ \\
\hline \multirow[t]{2}{*}{ tolC } & TACCCAGGCGCAAAAAGAGGCTATC & 161 \\
\hline & CCGCGTTATCCAGGTTGTTGC & \\
\hline \multirow[t]{2}{*}{$c d t B$} & ACAACTGTCGCATCTCGCCCCGTCATT & 268 \\
\hline & CAATTTGCGTGGGTTCTGTAGGTGCGAGT & \\
\hline \multirow[t]{2}{*}{ sitC } & CAGTATATGCTCAACGCGATGTGGGTCTCC & 768 \\
\hline & CGGGGCGAAAATAAAGGCTGTGATGAAC & \\
\hline \multirow[t]{2}{*}{ spiA } & CCAGGGGTCGTTAGTGTATTGCGTGAGATG & 550 \\
\hline & CGCGTAACAAAGAACCCGTAGTGATGGATT & \\
\hline \multirow[t]{2}{*}{$\operatorname{sop} B$} & CGGACCGGCCAGCAACAAAACAAGAAGAAG & 220 \\
\hline & TAGTGATGCCCGTTATGCGTGAGTGTATT & \\
\hline \multirow{2}{*}{$\operatorname{lpfC}$} & GCCCCGCCTGAAGCCTGTGTTGC & 641 \\
\hline & AGGTCGCCGCTGTTTGAGGTTGGATA & \\
\hline \multirow[t]{2}{*}{ sifA } & TTTGCCGAACGCGCCCCCACACG & 449 \\
\hline & GTTGCCTTTTCTTGCGCTTTCCACCCATCT & \\
\hline \multirow[t]{2}{*}{$\operatorname{spv} B$} & CTATCAGCCCCGCACGGAGAGCAGTTTTTA & 717 \\
\hline & GGAGGAGGCGGTGGCGGTGGCATCATA & \\
\hline \multirow[t]{2}{*}{ pefA } & GCGCCGCTCAGCCGAACCAG & 157 \\
\hline & GCAGCAGAAGCCCAGGAAACAGTG & \\
\hline \multirow[t]{2}{*}{$\operatorname{sip} B$} & GGACGCCGCCCGGGAAAAACTCTC & 875 \\
\hline & ACACTCCCGTCGCCGCCTTCACAA & \\
\hline
\end{tabular}

En todos los ensayos se procesó como control positivo la cepa Salmonella Typhimurium ATCC 14028 bajo las mismas condiciones que los aislados.

La reacción de amplificación de los genes se llevó a cabo bajo las siguientes condiciones: desnaturalización inicial $95^{\circ} \mathrm{C}$ por 5 min, 30 ciclos de desnaturalización a $94{ }^{\circ} \mathrm{C}$ por $30 \mathrm{~s}$, hibridación a $66.5^{\circ} \mathrm{C}$ por $30 \mathrm{~s}$, extensión a $72{ }^{\circ} \mathrm{C}$ por $1 \mathrm{~min}$, y una extensión final a $72{ }^{\circ} \mathrm{C}$ por $10 \mathrm{~min}$, en un termociclador MyCycler (Bio-Rad). Los productos de PCR fueron analizados mediante electroforesis en un gel de agarosa al $2 \%$, con TBE $0.5 \mathrm{X}$ como buffer de corrida a $100 \mathrm{~V}$ y $100 \mathrm{~mA}$ por $1 \mathrm{~h}$. Para visualizar las bandas de ADN se utilizó bromuro de etidio como revelador, y el tamaño de los amplificados fueron determinados con un marcador de peso molecular de 100 pb (DNA Ladder, Gene Ruller, Fermentas). 


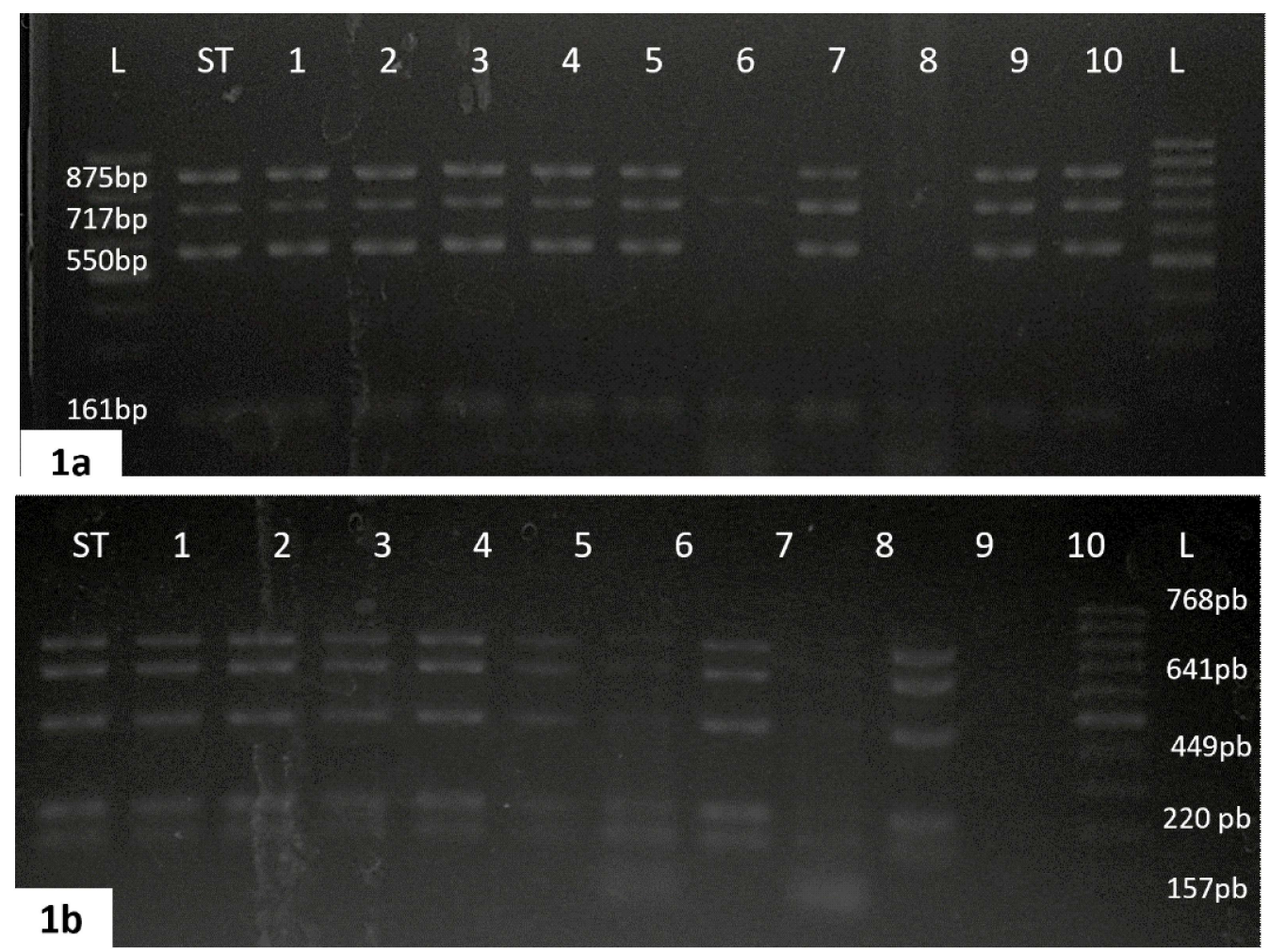

Figura 1. Detección de factores de virulencia de Salmonella Typhimurium aislados de cuyes sanos y enfermos mediante PCR múltiple. 1a) Los productos amplificados obtenidos son $\operatorname{SipB}(875 \mathrm{pb}), \operatorname{SpvB}(717 \mathrm{pb}), \operatorname{Sip} A(550 \mathrm{pb})$ y tolC $(161 \mathrm{pb})$. L= Marcador de peso molecular $100 \mathrm{pb} . \mathrm{ST}=\mathrm{ATCC} 14028.1-10=$ orden de cepas analizadas. El gen $c d t B$ (268 bp) no fue amplificado en ningún caso. 1b) Productos amplificados son SitC (768 pb), lpfc (641 pb), SifA (449 pb), SopB (220 pb) y pefA (157 pb)

\section{Análisis de Datos}

Los resultados se expresaron en porcentajes organizados en tablas de doble entrada. Así mismo, se usó la prueba exacta de Fisher para determinar la asociación entre la presencia o ausencia de cada gen y el aparentemente estado sanitario de los cuyes, con un nivel de confianza de $95 \%$.

\section{Resultados y Discusión}

Se evaluó la presencia de 10 genes que codifican factores de virulencia en Salmonella Typhimurium aislados de cuyes apa- rentemente sanos ( $\mathrm{n}=10$ aislados) y enfermos ( $\mathrm{n}=90$ aislados). Estos genes pudieron ser detectados mediante el uso de la técnica de PCR Múltiple: la primera reacción permitió evaluar los genes tolC (161 pb), cdtB (268 $\mathrm{pb})$, sip $A(550 \mathrm{pb}), \operatorname{spv} B$ (717 pb) y sipB (875 pb) (Figura 1a) y la segunda reacción amplificó fragmentos de los siguientes genes: $p e f A$ (157 pb), sopB (220 pb), sifA (449 pb), lpfC $(641 \mathrm{pb})$ y $\operatorname{sit} C(768 \mathrm{pb})$ (Figura 1b).

Los 10 genes de virulencia evaluados en aislados de $S$. Typhimurium de cuyes aparentemente sanos y enfermos presentaron altos porcentajes de detección, los cuales se encuentran entre el 66 al 100\% y entre 65.6 
Cuadro 2. Presencia de genes de virulencia (\%) y Test exacto de Fisher en aislados $S$. Typhimurium de cuyes

\begin{tabular}{cccc}
\hline $\begin{array}{c}\text { Gen de } \\
\text { virulencia }\end{array}$ & \multicolumn{3}{c}{ Frecuencia (\%) } \\
\cline { 2 - 4 } & $\begin{array}{c}\text { Sanos } \\
(\mathrm{n}=90)\end{array}$ & $\begin{array}{c}\text { Enfermos } \\
(\mathrm{n}=10)\end{array}$ & $\begin{array}{c}\text { Fisher } \\
\text { test* }\end{array}$ \\
\hline TolC & 100 & 88.9 & 0.59 \\
CdtB & 0 & 0 & N.A. \\
SipA & 80 & 83.3 & 0.68 \\
SpvB & 80 & 83.3 & 0.68 \\
SipB & 60 & 78.9 & 0.23 \\
PefA & 100 & 73.3 & 0.11 \\
SopB & 90 & 73.3 & 0.44 \\
Sifa & 70 & 65.6 & 1.0 \\
LpfC & 80 & 73.3 & 1.0 \\
SitC & 60 & 73.3 & 0.46 \\
\hline
\end{tabular}

* Nivel de confianza: $95 \%$

N.A. = No Aplicable

al $88.9 \%$, respectivamente (Cuadro 2); sin diferencia estadística entre estos grupos de porcentajes de detección de genes de virulencia.

Los genes $\operatorname{sip} B, \operatorname{sit} C$ y $\operatorname{sop} B$ ubicados en la Isla de Patogenicidad de Salmonella 1 o SPI-1 (Perret y Zhou, 2013; Kim y Lee, 2017); spiA y sifA ubicados en SPI-2 (Figueroa y Verdugo, 2005; Kim y Lee, 2017) y el gen $\operatorname{lpfC}$, el cual es un operon fimbrial (Sabbagh et al., 2010) se detectaron en un porcentaje variable entre 65.6 y $83.3 \%$; presentándose en mayor frecuencia los genes spiA $(83.3 \%)$ y sipB $(78.9 \%)$ dentro de los aislados de cuyes enfermos. En el caso de los aislados de S. Typhimurium de cuyes aparentemente sanos se obtuvieron frecuencias entre 60 al $90 \%$, siendo el gen predominante sopB, el cual se presenta en el $90 \%$ de los aislados. Por otro lado, los genes codificados en plásmidos de virulencia, pefA y $\operatorname{spv} B$ (Pilla y Tang, 2018) se detectaron en el $73.3 \mathrm{y}$ $83.3 \%$ en los aislados de cuyes enfermos, respectivamente, mientras que en los aislados de cuyes aparentemente sanos, pefA y $s p v B$ se presentaron en el 100 y $80 \%$ de los casos; y, finalmente, el gen tolC, de origen cromosómico, se presentó en mayor frecuencia en todos los aislados, apareciendo en el $88.9 \%$ de aislados de cuyes enfermos y en el $100 \%$ de aislados de cuyes aparentemente sanos. El gen $c d t B$, codificado en la Isla de Patogenicidad 11 (SPI-11) en Salmonella Typhi (Sabb agh et al., 2010) no fue identificado en los aislados de este estudio.

Dicha similitud entre cepas de animales enfermos y sanos podría relacionarse con la ubicación de los genes mencionado previamente. A nivel de las diversas Islas de Patogenicidad de Salmonella (SPI), la adquisición de una SPI puede convertir un microorganismo comensal en patógeno; sin embargo, este proceso no es un garante de la transformación del microorganismo, pues la virulencia dependerá tanto de la bacteria receptora y del hospedero (Marcus et al., 2000; Martínez, 2007). En relación a este último, es conocido que cambios a nivel de la microbiota autóctona intestinal, debido a la administración de antimicrobianos, ocasionan que la carga bacteriana potencialmente patógena aumente considerablemente (Casadevall, 2017); de forma similar, los genes localizados en plásmidos de virulencia (Martínez, 2007), se propagan por transferencia horizontal (Pilla y Tang, 2018); sin embargo, se conoce que no todos los miembros de un mismo serovar contienen el plásmido de virulencia, sino que su presentación suele ser variable en serovares con amplio rango de hospederos, como es el caso de Salmonella Typhimurium (Silva et al., 2017).

El relación al gen tolC, cuyo origen cromosómico confiere importancia durante la colonización e infección del hospedero, secreción y exportación de moléculas y toxinas, capacidad innata de multidrogo resistencia, con lo que es esperable su alta frecuencia de detección por tratarse de un gen altamente conservado en todos los serovares de 
Salmonella (Horiyama et al., 2010; Ricci y Piddock, 2010), donde el knockout del mismo anula su capacidad de supervivencia en la célula hospedera, a pesar que la bacteria aún puede replicarse (Buckley et al., 2006).

No se encontraron diferencias estadísticas en los porcentajes de detección de cada gen de virulencia entre los cuyes aparentemente sanos y enfermos (Cuadro 2); es decir, no hubo asociación aparente entre la presentación individual de los genes de $S$. Typhimurium con el estado sanitario del cuy, concluyendo que no había relación entre genes de virulencia y estados de salud y enfermedad. Con ello, estos resultados son semejantes a los obtenidos en otros trabajos, tal es el caso de Skyberg et al. (2006) quienes evaluaron el mismo panel de genes de virulencia en $S$. Typhimurium procedentes de aves de producción sanas y enfermas, sin hallar diferencia entre cepas; o como lo reportado por Tamang et al. (2014), quien es detectaron que más del 96\% de aislados analizados de cerdos enfermos y sanos poseían diversos genes de virulencia, incluídos spiA, $\operatorname{sip} B$, tolC, lpfC, sifA, sitC y $\operatorname{sop} B$; $\sin$ embargo, la prevalencia de dichos genes en cerdos enfermos se asociaron además a fenotipos multiresisitentes a antimicrobianos, lo cual los convierte en aislados potencialmente más peligrosos que constituyen un riesgo a la salud pública.

Por último, es importante mencionar que Salvatierra et al. (2018) establecieron un solo grupo genético de $S$. Typhimurium, el cual sigue una dispersión clonal entre los centros de producción intensiva de cuyes en Lima, similar a lo obtenido en este estudio. Por ello, la presencia de un patrón de alta homogeneidad genética de factores de virulencia de Salmonella Typhimurium aislados de cuyes tanto enfermos como aparentemente sanos debería ser tomado en consideración, pues representaría un potencial riesgo para la producción, donde dichos animales podrían actuar como portadores asintomáticos y diseminadores de la enfermedad (Schultz et al., 2018).

\section{Conclusiones}

- Los aislados de Salmonella Typhimurium presentaron 9 de los 10 factores de virulencia evaluados, con frecuencias variables y mayores al $60 \%$, tanto en cuyes enfermos como aparentemente sanos.

- No se encontró diferencia significativa entre los factores de virulencia presentes en aislados de Salmonella Typhimurium provenientes de cuyes enfermos y aparentemente sanos.

- No se encontró asociación entre la presentación individual de los factores de virulencia de $S$. Typhimurium evaluados y el estado sanitario del cuy.

\section{Literatura CitAda}

1. Buckley A, Webber M, Cooles S, Randall L, La Ragione R, Woodward M, Piddock L. 2006. The AcrAB-TolC efflux system of Salmonella enterica serovar Typhimurium plays a role in pathogenesis. Cell Microbiol 8: 847-856. doi: 10.1111/j.1462-5822.2005.00671.x

2. Casadevall A. 2017. The pathogenic potential of a microbe. mSphere, 2(1). doi: 10.1128/msphere.00015-17

3. Chauca L. 1997. Producción de cuyes (Cavia porcellus). Organización de las Naciones Unidas para la Agricultura y la Alimentación - FAO. Roma, Italia. [Internet]. Disponible en: http:// www. fao.org/DOCREP/W6562s/ W6562s00.htm

4. Chero A, Rosadio R, Marcelo G, Díaz $G$, Jiménez R, Castro Y, Maturrano L. 2017. Identificación molecular de Salmonella typhimurium en cuyes al primer parto mediante la técnica de PCR múltiple. Rev Inv Vet Perú 28: 679-686. doi: 10.15381/rivep.v28i3.13288

5. Figueroa IM, Verdugo A. 2005. Mecanismos moleculares de patogenicidad de Salmonella sp. Rev Latinoam Microbiol 47: 25-42. 
6. Flores L. 2003. Caracterización fenotípica y genotípica de estirpes de Salmo-nella choleraesuis aisladas de ambientes marinos. Tesis de Biología. Lima, Perú: Univ. Nacional Mayor de San Marcos. 142 p.

7. Horiyama T, Yamaguchi A, Nishino K. 2010. TolC dependency of multidrug efflux systems in Salmonella enterica serovar Typhimurium. J Antimicrob Chemother 65: 1372-1376. doi: 10.1093/ $\mathrm{jac} / \mathrm{dkq} 160$

8. Karimnasab N, Tadayon K, Khaki P, Bidhendi S, Ghaderi R, Sekhavati M, Asadi F. 2013. An optimized affordable DNA-extraction method from Salmonella enterica Enteritidis for PCR experiments. Archiv Razi Inst. 68: 105-109.

9. Kim JE, Lee YJ. 2017. Molecular characterization of antimicrobial resistant non-typhoidal Salmonella from poultry industries in Korea. Ir Vet J 70: 20. doi: 10.1186/s13620-017-0095-8

10. Krawiec M, Kuczkowski M, Kruszewicz A, Wieliczko A. 2015. Prevalence and genetic characteristics of Salmonella in free-living birds in Poland. BMC Vet Res 11: 15. doi: 10.1186/ s12917-015-0332-x

11. Marcus SL, Brumell JH, Pfeifer CG, Finlay BB. 2000. Salmonella pathogenicity islands: big virulence in small packages. Microbes Infect 2: 145-156. doi: 10.1016/s1286-4579(00)00273-2

12. Martínez N. 2007. Virulencia, resistencia y elementos genéticos móviles en serotipos no prevalentes de Salmonella enterica. Tesis Doctoral. España: Univ. de Oviedo. $154 \mathrm{p}$.

13. Mather AE, Lawson B, de Pinna E, Wigley P, Parkhill J, Thomson NR, Page AJ, et al. 2016. Genomic analysis of Salmonella enterica serovar typhimurium from wild passerines in England and Wales. Appl Environ Microbiol 82: 67286735. doi: 10.1128/AEM.01660-16

14. Matsuura A, Morales S, Calle S, Ara M. 2010. Susceptibilidad a antibacterianos in vitro de Salmonella enterica aislada de cuyes de crianza familiar-comercial en la provincia de Carhuaz, Áncash. Rev Inv Vet Perú 21: 93-99. doi: 10.15381/rivep.v21i1.355

15. Mezal EH, Sabol A, Khan MA, Ali N, Stefanova R, Khan AA. 2014. Isolation and molecular characterization of Salmonella enterica serovar Enteritidis from poultry house and clinical samples during 2010. Food Microbiol 38: 67-74. doi: 10.1016/j.fm.2013.08.003

16. Morales S, Mattos J, Calle S. 2007. Efectos de la muña (Satureja parvifolia) en la dinámica de la infección por Salmonella entérica en cobayos. En: XXX Reunión Científica Anual de la Asociación Peruana de Producción Animal. Cusco, Perú: APPA.

17. Morales $S$. 2012. Patógenos oportunistas por transmisión fecal-oral en cuyes reproductores introducidos al distrito de San Marcos. Científica 9: 33-38.

18. Murugkar HV, Rahman H, Dutta PK. 2003. Distribution of virulence genes in Salmonella serovars isolated from man \& animals. Indian J Med Res 117: 66-70.

19. Perrett CA, Zhou D. 2013. Salmonella type III effector SopB modulates host cell exocytosis. Emerg Microbes Infect 2: e32. doi: 10.1038/emi.2013.31

20. Pilla G, Tang CM. 2018. Going around in circles: virulence plasmids in the enteric pathogens. Nat Rev Microbiol 16: 484-495. doi: 10.1038/s41579-018-0031-2

21. Ricci V, Piddock LJ. 2010. Exploiting the role of $T o l C$ in pathogenicity: identification of a bacteriophage for eradication of Salmonella serovars from poultry. Appl Environ Microbiol 76: 17041706. doi: 10.1128/AEM.02681-09

22. Sabbagh SC, Forest CG, Lepage C, Leclerc JM, Daigle F. 2010. So similar, yet so different: uncovering distinctive features in the genomes of Salmonella enterica serovars Typhimurium and Typhi. FEMS Microbiol Lett 305: 1-13. doi: 10.1111/j.1574-6968.2010.01904.x 
23. Salvatierra G, Rímac R, Chero A, Reyna I, Rosadio R, Maturrano $L$. 2018. Resistencia antimicrobiana y genotipificación de cepas de Salmonella Typhimurium aisladas de cuyes (Cavia porcellus) provenientes de granjas de producción intensiva de la ciudad de Lima, Perú. Rev Inv Vet Perú 291: 319327. doi: 10.15381/rivep.v29i1.14089

24. Sánchez LC, Corrales R. 2005. Evaluación de la congelación para conservación de especies autóctonas bacterianas. NOVA 3: 21-29. doi: 10.22490/ 24629448.333

25. Schultz BM, Salazar GA, Paduro CA, Pardo-Roa C, Pizarro DP, SalazarEchegarai FJ, Torres J, et al. 2018. Persistent Salmonella enterica serovar Typhimurium infection increases the susceptibility of mice to develop intestinal inflammation. Front Immunol 9: 1166. doi: 10.3389/fimmu.2018.01166
26. Silva C, Puente JL, Calva E. 2017. Salmonella virulence plasmid: pathogenesis and ecology. Pathog Dis 75: ftx070. doi: 10.1093/femspd/ftx070

27. Skyberg JA, Logue CM, Nolan LK. 2006. Virulence genotyping of Salmonella spp with multiplex PCR. Avian Dis 50: 77 81. doi:10.1637/7417.1

28. Tamang MD, Gurung M, Nam HM, Moon DC, Jang GC, Jung SC, Lim SK. 2014. Antimicrobial susceptibility and virulence characteristics of Salmonella enterica Typhimurium isolates from healthy and diseased pigs in Korea. J Food Prot 77: 1481-1486. doi: 10.4315/ 0362-028X.JFP-14-084

29. van Asten AJ, van Dijk JE. 2005. Distribution of «classic» virulence factors among Salmonella spp. FEMS Immunol Med Microbiol 44: 251-259. doi: 10.1016/ j.femsim.2005.02.002 